\title{
REGIONAL EXPERIENCES: WHAT HAVE WE LEARNED?
}

Keijiro Otsuka and Shenggen Fan

The five chapters on regional issues in agricultural development provide an overview of the various regional experiences and the transformation of agrifood systems. In these chapters, as well as in Chapter 1, the validity of the Hayami-Ruttan induced innovation hypothesis (Hayami and Ruttan 1985) was graphically examined, particularly by looking at growth paths of land and labor productivities in various countries and across major regions. Also examined were emerging trends of agricultural transformation in these regions. This chapter summarizes regional experiences in productivity growth and agricultural transformation.

\section{Regional Experiences in Productivity Growth}

As can be seen from Figure 1.1 in Chapter 1, there are enormous differences and changes in labor productivity among the seven major regions over the last several decades. Such large differences in labor productivity can be partly attributed to the difference in factor endowment represented by the land-labor ratio. Roughly speaking, there is a positive correlation between labor productivity and the land-labor ratio, with the possible exception of Latin America and the former Soviet Union countries. If land is abundant relative to labor, farm size is large and mechanized operation is economical, whereas if land is scarce, farm size is small and labor-intensive operation is advantageous. The close relationship between the land-labor ratio and labor productivity is clearly reported in Chapters 3 to 7.

The five regional chapters also show the close relationship between fertilizer use per unit of land and land productivity, which indicates the importance of fertilizer-using technology to boost land productivity. Land productivity has been growing rapidly and is second highest in South America, even though it is endowed with rich land resources. Land productivity in East Asia, where land is particularly scarce, was growing fast in the 1970s and 
1980s due, in part, to the yield-enhancing Green Revolution technologies, but its level was not highest in this early period.

Figure 1.2 in Chapter 1 shows the changing relationship between labor and land productivities, with the logarithm of labor productivity on the horizontal axis and that of land productivity on the vertical axis. It is clear that East Asia took the high-land-productivity development path. In Asia where land is scarce, land-saving and yield-enhancing technologies tend to be developed. Subsequently, labor cost increases due to rapid development of the nonfarm sectors, which leads to the development of labor-saving and labor-productivity-enhancing technology more than that of land-productivityenhancing technology. An interesting finding is that not only South Asia but also Africa south of the Sahara (SSA) seem to have been following the East Asian path. Indeed, it seems that South Asia is attempting to catch up with East Asia (see Chapter 4) and that SSA follows the South Asian path so long as smallholder-based agriculture is maintained (Chapter 5).

A close examination reveals that Eastern Europe improved primarily its labor productivity, whereas both South America and Mexico and Central America improved both labor and land productivity simultaneously. Although Latin American countries are characterized by land abundance, they have successfully introduced land-saving and land-productivity-enhancing technologies while maintaining the impetus to improve labor productivity growth. This seems inconsistent with the Hayami-Ruttan hypothesis. Endowed with extremely rich land resources, the former Soviet Union countries follow a unique path of low land productivity and high labor productivity.

The above analysis points out that the induced innovation hypothesis is broadly consistent with the recent data in many regions, even though there are also deviations from the expected patterns of land and labor productivity growth, particularly in Latin America and the former Soviet Union countries. Regional experiences also point to limitations of Hayami and Ruttan's narrow focus on grain productivity and growth. A major departure from the Hayami-Ruttan thesis can be found in the modern food system transformation at both regional and global levels, where the demands on agriculture now go beyond food to encompass health, nutrition, and environmental sustainability. For instance, the Hayami and Ruttan (1985) measures of productivity are at the farm level. But the food system transformation involves postfarm value addition. In addition, the essence of the modern value chains lies in the demand-driven activities throughout the whole chains, which in turn lead to innovations in technologies and institutions. Technologies used or adopted are increasingly coming from nonagriculture or the private food sector and 
are not induced by land-labor ratio changes: for example, information and communication technologies (ICTs). Finally, environmental externalities and climate change were not considered in the Hayami and Ruttan model. Clearly we must have broader perspectives than Hayami and Ruttan in order to understand the rapid transformation of agriculture over the last few decades and its implication for global issues.

\section{Transformation of Agriculture}

In East Asia, industrialization has led to the large-scale transformation of the agricultural sector on the production side through a reduction in its contribution to gross domestic product and employment, and it also has created a serious labor shortage and thus a rapid increase in real wages. At the same time, the rising demand for safe, high-value, and differentiated agricultural products driven by the nutrition transition has created large opportunities for farmers to participate in emerging value chains to potentially improve productivity and increase incomes. As farming systems gradually change from labor-intensive to capital-intensive systems, technological and institutional innovations have occurred, such as in farm machinery and machine service providers and emerging e-commerce. There has been a notable modernization of value chains and emergence of contract farming on the supply side, which respond to diverse and new food demands especially driven by rapid urbanization and the rise of ICTs.

South Asia has been shifting toward the beginning of agricultural transformation, with greater increases in labor productivity than in land productivity, as experienced by many developed countries in the past. There has been significant mechanization growth in the past three decades, coupled with technological innovations, ranging from the adoption of machines and chemicals to improved varieties, increasingly led by the private sector in the region. Institutional innovations have raised the efficiency of agricultural finance, insurance provision on a broader scale, and collective action in milk production, improved food safety practices, and management of common pool resources, including irrigation facilities and community forests. Liberalization and regional integration have also facilitated the trade of agricultural commodities within the region and improved national resilience against food crises.

Africa, after decades of stagnation, has enjoyed sustained agricultural growth since 2000, while poverty rates have also fallen significantly. Africa's workforce is shifting, in some cases quite rapidly, with a rising fraction of 
labor moving from farming to off-farm sectors, even if the rural population continues to grow and average farm sizes continue to fall across most of the continent. Africa's delayed demographic transition ensures a continuously rising absolute number of rural people despite urbanization, leading to falling land-labor ratios. Thus, there is need for more labor-using, land-saving innovation in most of Africa, even though the rest of the world proceeds to mechanize (Chapter 5; Masters et al. 2018). Agribusiness and downstream food systems are responding dynamically to population growth and urbanization. Changing food diets associated with income growth and urbanization are creating new employment opportunities in agrifood systems. Urbanization and development of food systems to feed growing cities are also reshaping African farmers' access to markets, as secondary cities are emerging and extending the reach of value chains into areas formerly considered remote. There has been greater vibrancy of agricultural land markets as well as a rise of commercialized African investor farmers, especially in products with scale economies, such as poultry and horticulture. At the same time, African governments have brought agriculture back to the top of their development agendas, while the private sector is also increasingly investing in agriculture.

The agriculture sector in Latin America and the Caribbean has had relatively strong performance during the last several decades. Policy changes related to macroeconomic stabilization and liberalization have led to a significant diversification of agricultural production. Gains in the region's agriculture have been driven by productivity improvement as well as significant expansion of agricultural area over the last half century. These changes have been accompanied by an increase in nonagricultural rural activities, with a larger presence of women's employment and growth in urban residence, helped by better rural infrastructure. Food value chains have also evolved significantly, with increased urbanization and a larger presence of intermediate cities, and with agricultural and agro-industrial activities increasingly controlled by large agricultural operators, input companies, agro-industrial processors, and supermarket chains. Waves of changes in the processing and retail segments, such as the expansion of supermarkets, have occurred with a surge of foreign direct investments (FDI).

Eastern Europe and Central Asia (ECA) has shown several patterns of agricultural growth, including strong labor productivity growth from large farms as well as land productivity growth in poorer countries dominated by small farms. Agricultural productivity growth in the region has been strongly influenced by value-chain investments, up- and downstream from the farms. Private investments in agribusiness, food processing, and retailing have also 
led to important restructuring in production and trading and marketing systems and in the integration of farms in value chains. Contract farming and vertical coordination in these supply chains have played important roles in the process of restructuring, together with a variety of institutional innovations such as provision of credit, inputs, transportation, and quality control. As in some other regions, investments in the value chains often came from FDI, which has reduced capital constraints, making access to inputs and technology easier and stimulating productivity growth.

\section{Issues Addressed in Subsequent Chapters}

It is clear that significant and rapid transformation of agriculture and food value chains, as well as nutrition transition, have been taking place in various regions associated with urbanization and income growth. Also observed are rapid expansion of agricultural trade and reduction in trade distortions associated with trade liberalization. These issues will be discussed in Chapters 9 to 14. Other major changes include women's status, development of credit and insurance institutions, and natural resource management including land, forest, water, and climate change. This book will address these issues in Chapters 15 to 20, before presenting the analysis of the future of agricultural research in Chapter 21 and the reshaping of agrifood systems to achieve multiple development goals in Chapter 22 .

\section{References}

Hayami, Y., and V. W. Ruttan. 1985. Agricultural Development: An International Perspective.

Baltimore: Johns Hopkins University Press.

Masters, W. A., N. Z. Rosenblum, and R. G. Alemu. 2018. “Agricultural Transformation, Nutrition Transition and Food Policy in Africa: Preston Curves Reveal New Stylised Facts." Journal of Development Studies 54 (5): 788-802. 
